\title{
REDES SOCIAIS E PRÁTICAS ESCOLARES: PLATAFORMAS PARA UMA GEOGRAFIA ONLINE ${ }^{1}$
}

\author{
Élida Pasini Tonetto ${ }^{1}$ \\ ${ }^{1}$ Programa de Pós-Graduação em Geografia, Universidade Federal do Rio Grande do Sul. E-mail: elidapasinitonetto@gmail.com
}

Recebido em 07/2013. Aceito para publicação em 10/2013.

Versão online publicada em 19/09/2014 (http://seer.ufrgs.br/paraonde)

\begin{abstract}
Resumo: Este estudo analisa as potencialidades e operacionalidades de práticas escolares em Geografia na apropriação das redes sociais online para aprendizagens significativas. Para isso, identificamos os elementos impulsionadores de potencialidades oferecidas pelas plataformas digitais e avaliamos como ocorrem suas operacionalidades no ensino de Geografia. Com estas constatações possibilitaram refletir sobre os elementos que contribuem para a implementação de práticas escolares com redes sociais na Geografia. As linhas teóricas da pesquisa estão tramadas entre os conceitos de espaço, ciberespaço e transita também por dois locais fundamentais: o da escola e o das redes, locais estes que permeiam toda a discussão deste estudo. A abordagem teórico-metodológica está amparada nas pesquisas pós-críticas em educação por possibilitarem compreender como se dá o processo de aprender em plataformas digitais a partir de rasgos metodológicos trazidos pelas tecnologias contemporâneas. 0 Facebook é o lócus para analisar as novas formas de comunicar, que subjetivam os sujeitos e engendram novos formatos de ensinagem. Os resultados apontam diferentes potencialidades e operacionalizadas das redes sociais online, não representando apenas o uso da técnica em sala de aula, mas sim a busca pela construção de processos de aprendizagens significativos em Geografia, através das redes sociais, que representam uma linguagem contemporânea presente no cotidiano dos alunos.
\end{abstract}

Palavras - chave: Geografia Online - Tecnologias - Práticas Escolares

\section{Cliques iniciais}

Este estudo teve a intenção de analisar as potencialidades e operacionalidades das práticas pedagógicas da Geografia na apropriação das redes sociais online e refletir sobre os elementos que contribuem para implementação de práticas escolares com redes sociais na Geografia.

As motivações que moveram nossos olhares sob o espaço escolar estão relacionadas aos modos de viver dos jovens, permeados por novas maneiras de comunicar e informar, em especial através de dispositivos móveis que oferecem acesso a internet, permitindo intensa interação comunicativa entre eles.

Assim, recorremos apenas a uma das inquietações vivenciadas no espaço escolar, mas que consideramos mais latentes na atualidade, ou seja, as questões ligadas as diferentes maneiras de apropriação das tecnologias entre professores e alunos. Enquanto os alunos estão conectados e em interação através de seus dispositivos (celulares, tablets, notebooks), por outro lado os professores tem certo temor em recorrer a tais tecnologias no dia dia, e de modo especial em suas práticas.

Ao percebemos este panorama onde os alunos são de certo modo online e vivem na condição da sociedade contemporânea e os professores em sua grande maio- ria ainda não conseguem viver/por em prática plenamente esta condição em suas práticas, nos encaminhamos para reflexões sobre esta problemática, ao pensar em práticas escolares que possam contribuir para a diminuição desta distância entre alunos e professores e colaborar para a construção de uma aprendizagem mais significativa na Geografia.

Consideramos importante destacar que entendemos esta sociedade a qual nos referimos, em linhas gerais a partir de Bauman (2001), como líquida, leve e fluída, não estruturada e permeada por inseguranças, se contrapondo a ideia de solidez e de predomínio da racionalidade que marcou a modernidade. A partir destas ideias configura-se o contexto que entendemos neste estudo como pós-modernidade ou contemporaneidade, que vem enfraquecendo valores e instituições tradicionais, através de mecanismos como o consumo de massa, a tecnologia e a informação.

E a escola como integrante desta sociedade (e deste espaço/tempo) não esta imune do que com ela ocorre, sendo o seu reflexo e ao mesmo tempo o lócus onde a reflexão e discussão sobre esta mesma sociedade pode ocorrer. Neste sentido, pensar sobre as potencialidades das tecnologias na educação é de fundamental importância para analisar os modos de se comunicar/ agir/aprender dos jovens alunos usuários de tais tec- 
nologias.

Diante deste cenário, a escola enfrenta o enorme desafio de não ficar alheia e simplesmente ignorar estes novos potenciais tecnológicos que adentram seu espaço, com diferentes formas de acessar a informação e até mesmo de construir o conhecimento, e sim pensá-los em seus processos de planejamento e de práticas.

Assim, ao refletirmos sobre um estudo que pudesse contribuir para pensar a escola e as Tecnologias de Informação e Comunicação/TIC um recorte foi obviamente um sinistro necessário ao andamento da pesquisa científica. Entre tantos caminhos possíveis, consideramos relevante, no que se refere a aproximação das TIC e a Geografia, uma investigação sobre as chamadas redes sociais online, pois estas redes tem sido aderidas e apropriadas pelos jovens, que através delas vem construindo novas maneiras de comunicar.

A questão a qual se debruçou esta pesquisa refere-se então as potencialidades e operacionalidades das redes sociais nas práticas escolares da Geografia. Deste modo, a rede social online foi o lócus deste estudo para investigar as TIC, bem como a construção de práticas escolares em Geografia que considerem as possíveis potencialidades para apropriação destas redes sociais. Neste sentido, buscamos investigá-las a fim de procurar caminhos para a construção de formas de aprendizagem, que possam contemplar sujeitos/alunos imersos em um espaço/tempo onde as relações são cada vez mais interativas, com as possibilidades oferecidas pelas TIC.

\section{Contatos online}

No intricado processo de discutir espaço e ciberespaço destacamos que para Lemos (2010, p. 136) o ciberespaço tem o que "Deleuze e Guattari chamaram de estrutura rizomática. Uma estrutura rizomática é um sistema de multiplicidade, um sistema de bifurcações como um verdadeiro rizoma, uma extensão ramificada em todos os sentidos, sem centro". Para Lemos o rizoma é o que vai caracterizar o ciberespaço, sendo que o modelo dos filósofos franceses modernos foi a árvore, com a crise da modernidade o rizoma toma o lugar desta árvore.

É pertinente considerar também uma importante distinção feita por Graham (1998) e que Massey (2012) utiliza em sua discussão, sobre três diferentes maneiras de conceber a relação entre tecnologia da informação e espaço.

Primeiro, há o modo, que consideramos acima, que ele caracteriza como "substituição e transcendência: determinismo tecnológico, interatividade generalizada e o fim da geografia, e que ele critica do início ao fim por seu ingênuo determinismo tecnológico. Segundo, há o modo de "co-evolução: a produção social paralela de espaço geográfico e do espaço eletrônico" que, rejeitando o determinismo tecnológico, estabelece que os espaços eletrônico e territorial são, necessariamente, produzidos juntos. Terceiro, há o modo de "recombinação" que envolve a constituição mútua de tecnologia e esfera social (p. 146).

Este terceiro ponto é fundamental para um entendimento de um espaço e um ciberespaço construídos e reconstruídos mutuamente. No entanto, percebemos que algumas das ideias embasadas em Lemos (2010) apontam para o encaixe do segundo modo de conceber tecnologia e espaço, ou seja, como uma co-evolução, enquanto Massey (2012) parece estar mais próxima do terceiro modo, que se trata da recombinação.

Este estudo procurou realizar um esforço em tratar a relação entre tecnologia e espaço de modo recombinatório, procurando formas de romper com o binarismo, humano/tecnologia, fluidez/fixidez. Mas também considerando inúmeros pontos apresentados por Lemos que contribuem para o entendimento do que seria neste momento o ciberespaço. Especialmente no que se referem as suas potencialidades de leitura enquanto um rizoma, que oferece a possibilidade do "e" e não apenas do "ser" e enquanto um ambiente que apresenta forças sociais de compartilhamento comunitário entre as pessoas.

As redes podem ser estabelecidas de distintas formas, podemos formar redes sem a presença da tecnologia, cada pessoa cria suas próprias redes diariamente, rede de familiares, de amigos, de colegas de trabalho, de escola, de faculdade, de conhecidos; enfim, uma série de pessoas as quais nos conectamos em determinados momentos de nossas vidas. 0 que as tecnologias digitais fazem neste sentido é potencializar isso tudo, pois esse tipo de tecnologia "mais do que permitir aos indivíduos comunicar-se, ampliou a capacidade de conexão" (RECUERO, 2009, p. 50), assim podemos interagir com a rede por maior período de tempo e em diferentes espaços.

Neste sentido, podemos dizer que "a formação de redes de interação vem atingindo as mais diversas esferas e campos de conhecimento, desde o plano econômico, científico, cultural etc." (MACHADO, 2005, p. 02). $\mathrm{E}$ as tramas deste tecido tornam-se cada vez mais complexas, podendo ser entendidas como conexões que em conjunto formam as redes, potencializadas e complexificadas, sobretudo pela disponibilização de novas tecnologias da comunicação.

Com isto, é importante uma discussão sobre as redes sociais online, como um emergente recurso comunicacional, Recuero (2009) discute de forma intensa esta questão e segundo seu entendimento as redes sociais possuem um conjunto de dois elementos fundamentais que as constituem, são eles os atores, entendidos como pessoas instituições ou grupos participantes, que compõem os nós da rede, e as conexões, ou seja, as interações e laços sociais.

Assim, uma rede social "é uma metáfora para ob- 
servar os padrões de conexão de um grupo social, a partir das conexões estabelecidas entre os diversos atores" (RECUER0, 2009, p. 25), possuindo uma estrutura social, em que não é possível abordar separadamente os atores sociais de suas conexões. Estas trocas entre grupos sociais às quais estamos discutindo vem ocorrendo também em ambientes online, amparadas por um aparato tecnológico, computadores, celulares, tablets, conexão a internet e especialmente softwares, que são os programas operacionalizadores das redes sociais online. Para exemplificar podemos citar os softwares sociais: Facebook, Orkut, Sonico, Twitter e etc.

Mesmo não sendo a rede social em si, os sites de redes sociais são extremamente importantes para se pensar a metáfora da rede, e a maneira peculiar de se comunicar e trocar informações do sujeito contemporâneo. "A grande diferença entre sites de redes sociais e outras formas de comunicação mediadas pelo computador é o modo como permitem a visibilidade e a articulação das redes sociais, a manutenção dos laços sociais estabelecidos no espaço off-line." (RECUERO, 2009, p. 102).

Esta ideia traz uma reflexão sobre o potencial de se apropriar, gerar e compartilhar informações que as redes sociais online possibilitam aos seus usuários, proporcionando a interação definida por Lévy (1999) como Todos-Todos, diferindo-se de outros veículos de comunicação, onde o sistema de interação é do tipo Um-Um ou Um-Todos. Assim, uma rede social online pode conferir a possibilidade de interferir/transformar/aprender de forma diferente determinada realidade, através desta nova lógica interacional oferecida ao usuário.

Podem ser pensadas ainda potencialidades das redes sociais no que se refere aos processos de aprendizagem dos sujeitos, mas poucos estudos foram encontrados sobre esta questão. Um potencial foi discutido por Santana (2007, p. 06) que

concebendo a produção de aprendizagem enquanto processo social e que, portanto, acontece em interação com o outro, é que considero de suma importância as relações sociais que se instituem no espaço virtual, mais propriamente em redes sociais da Internet. Visto que os sujeitos imersos nestas redes estão em constante intercâmbio com outros sujeitos, comunicando-se, trocando ideias, informações, compartilhando saberes.

Deste modo, percebe-se que o tema das redes sociais online e das interações nelas estabelecidas é complexo, e o que aparentemente serve apenas para comunicar ou divertir pode na verdade ser um excelente instrumento cultural para se pensar sobre o modo de ser/aprender/agir do sujeito contemporâneo. Assim, para refletir sobre as TIC e ir além do sentido de ferramenta, usamos o conceito de educação online que é uma modalidade de educação que pode ser vivenciada e exercitada tanto para potencializar situações de aprendizagem mediadas por encontros presenciais; totalmente à distância, caso os sujeitos do processo não possam ou não queiram se encontrar face a face; ou híbridos, onde os encontros presenciais podem ser combinados com encontros mediados por tecnologias telemáticas (SANTOS, 2005, p. 322).

Com este entendimento, propomos nesta investigação que a modalidade da educação online seja pensada/experimentada nas aulas de Geografia da escola básica, a partir da ideia de um híbrido entre educação presencial combinada com encontros mediados por TIC. Destacando que

a transformação e evolução das interfaces comunicacionais interativas e de conteúdos multimidiáticos e hipertextuais emergentes das tecnologias do ciberespaço e dos ambientes virtuais de aprendizagem pode potencializar processos significativos de aprendizagem. Entretanto, não garantem por si só a emergência de processos formativos de boa qualidade. Processos estes que façam emergir autorias individuais, coletivas e, sobretudo, autorias cidadãs (SANTOS, 2005, p. 319).

Nesta perspectiva, com tanta informação disponível, permanecer no papel de professor/transmissor não responde mais as necessidades do tempo contemporâneo. Deste modo, o grande desafio como professora de Geografia em interface com as TIC, e em especial com as redes sociais, é de construir um posicionamento de mediação/orientação.

Esta mediação torna-se de extrema relevância quando se analisa a enorme quantidade de informações disponíveis na internet, pois localizar dados utilizando buscadores é uma tarefa a qual a maioria dos jovens já sabe realizar com habilidade. No entanto, conectar estas informações e transformá-las em conhecimento é ainda uma habilidade que precisa ser desenvolvida.

Esta discussão se adere aos apontamentos sobre a sociedade contemporânea, que nos indicam uma corrosão das bases modernas das instituições, e dentre elas está a instituição escolar. As ponderações feitas por autores como Sibilia (2012) e Veiga-Neto (2008) apontam que as sólidas estruturas escolares estão sendo solapadas, em parte por um novo imperativo que se instala a partir da disseminação de um determinado tipo de tecnologia.

Neste sentido, Tonini afiança "a sociedade contemporânea está estruturada pela tecnologia. Isto é a ordem do dia para todos os seus segmentos quer no econômico, social ou cultural e em escalas mundiais" (2013, p. 49). Cabe neste ponto um questionamento pertinente, que tecnologias são estas? Que forças são 
estas capazes de corroer as bases de uma sociedade que se dizia sólida?

A resposta não é uma tarefa fácil, pois estamos no interior deste processo e delineá-lo claramente não é totalmente possível, mas alguns indícios esboçados por vários pensadores (CASTELLS, 2009; LÉVY, 1999; LEMOS, 2010; SIBILIA, 2012) convergem para um ponto: há uma ruptura entre um mundo estruturado pelas tecnologias chamadas analógicas e outro atravessado pelas tecnologias digitais.

Assim, é possível observar um intenso mal estar entre as sólidas estruturas escolares e as flexíveis redes que penetram através de seus meus membros, gerando novos e inesperados conflitos, bem como outras formas de relacionamento entre pessoas e entre estes e as informações.

Deste modo, o espaço da escola é entendido em seu sentido institucional, sendo analisado neste estudo a crise que se estabelece nesta instituição nos tempos em que estamos vivenciando, tempos de transição entre pensamentos herdados da modernidade e entre novas formas de pensar/agir advindas do emergente pensamento contemporâneo. 0 termo crise é utilizado no sentido de uma ruptura, para entendê-la se discute o mal estar presente no posicionamento de dois importantes atores do cenário escolar: professores e alunos.

O espaço das redes é entendido como os laços e conexões estabelecidos entre as pessoas, que vêm sendo potencializadas pelas tecnologias digitais. Neste sentido as redes sociais são tomadas neste estudo como um importante nó destas redes e um complexo instrumento contemporâneo que permite analisar os modos de comunicar dos sujeitos que transitam por elas.

Levando em consideração estas complexas lógicas que permeiam as relações nos espaços escolares atravessados pelas redes, procuramos construir práticas escolares em Geografia que considerem as dinâmicas presentes nestas redes a fim de procurar contemplar os sujeitos/alunos imersos em um espaço/tempo cada vez mais mediados por lógicas comunicacionais interativas e digitais.

\section{Modos de pensar e fazer}

Para entender melhor as estratégias que foram construídas para a condução da pesquisa, destacamos que utilizamos uma importante definição dos Estudos Culturais que defendem "que existe pedagogia, modos de ensinar e possibilidades de aprender nos mais diferentes artefatos culturais" (PARAÍSO, p. 24, 2012). Deste modo, foi utilizado neste estudo o artefato cultural Facebook, que é uma rede social online, por entendermos que de algum modo o mesmo tem o potencial de ensinar.

Deste modo, adotamos o Facebook como lócus para analisar as novas formas de comunicar que subjetivam os sujeitos e engendram novos formatos de ensinagem, concebendo esta rede social não apenas como uma ferramenta, mas como nos diz Pretto (1996), como "uma verdadeira máquina estruturante de novas formas de pensar, sentir e agir em nosso tempo".

Podemos dizer que a rede social online foi o local a partir do qual foram pensadas as formas de aprender relacionadas aos artefatos culturais contemporâneos, e as práticas pedagógicas da Geografia foram construídas de modo a se apropriarem da concepção destas redes sociais a fim de pensar caminhos para a construção de novas formas de aprendizagem significativa em Geografia. As análises foram efetuadas a partir de duas frentes principais, que não serão isoladas e sim em interface uma com a outra: o ciberespaço e o espaço.

O ciberespaço foi na prática representado pela rede social Facebook e o espaço pela escola e pelas às vivências que no decorrer da pesquisa tivemos imersas no espaço escolar, bem como na sala de aula da turma de alunos participantes. Deste modo, foi necessário articular dois procedimentos metodológicos diferentes, a etnografia educacional e a netnografia, que se mostraram ferramentas adequadas aos caminhos que tomados na investigação.

Nos momentos da investigação que estivemos "trilhando" pela etnografia educacional foram realizadas pesquisas a campo na Escola Estadual de Ensino Médio Arthur da Costa e Silva em Capivari do Sul/RS, local de atuação enquanto professora/pesquisadora de Geografia. No decorrer do percurso investigativo utilizamos técnicas etnográficas, como o registro em diário de campo, as observações foram realizadas em todos os espaços da escola, mas em especial na sala de aula da turma do segundo ano de ensino médio participante do estudo.

Enquanto os procedimentos da netnografia foram utilizados através das interações entre professora/ pesquisadora, alunos e demais usuários nas redes, em especial do Facebook. E também na construção das propostas trabalho e nas discussões dos resultados e soluções, sendo relevante destacar que este material foi utilizado como dados de análise da pesquisa.

As observações foram realizadas na sala de aula de uma turma do segundo ano de ensino médio, sendo esta a amostra participante do estudo. A escolha pelo segundo ano do ensino médio, se deu especialmente pelo fato dos alunos nesta etapa de sua vida escolar apresentar processos de autonomia e envolvimento mais profundos e maduros com as temáticas desenvolvidas na escola.

Além disso, no período destinado a prática de pesquisa, entre todas as turmas em que sou professora, essa era a que seria trabalhado um conteúdo conectado diretamente ao cotidiano dos alunos, o espaço urbano.

${ }^{2}$ Usamos o termo "Trilhando" no sentido de usar o corpo para andar/investigar pelo espaço da escola.

${ }^{3}$ Usamos o termo professora/pesquisadora, pois a pesquisadora Tonetto também é professora da turma de alunos participantes do estudo. 
Isto evidenciou um momento oportuno para construir aproximações entre a prática escolar da Geografia e a rede social Facebook, partindo de uma temática significativa para os alunos.

Ao explicitar as trilhas percorridas (escola) e as rotas navegadas (Facebook) no decorrer da investigação, é importante ressaltar que os registros detalhados e o rigor ético foram cuidadosamente implementados nesta pesquisa. No entanto, as metodologias adotadas estavam sempre a serviço da pesquisa e não ao contrário, nesta perspectiva, as ferramentas foram utilizadas a partir de uma postura metodológica de caráter aberto, flexível e reflexivo.

\section{Entre a sala de aula e o Facebook}

As análises do material empírico levaram em consideração as diferentes possibilidades de interagir propiciadas pelas tecnologias digitais, que permitem conexões entre as pessoas, e inflam nossas redes. Deste modo, procuramos nos aproximar destas formas de interação através da imersão na rede social Facebook, inserindo-a na prática escolar da Geografia, a qual demonstrou oferecer distintas potencialidades e operacionalidades.

Entre as paredes da sala de aula e as redes do $\mathrm{Fa}$ cebook a prática foi sendo construída, junto com alunos de uma turma do segundo ano do ensino médio. Primeiramente discutimos conceitos relacionados à Geografia urbana e aspectos da urbanização brasileira, após as discussões gerais, foi proposto aos alunos que em pequenos grupos identificassem problemas urbanos locais ou regionais significativos e fizessem uma explicação sobre o mesmo.

Com a análise do problema explicitada eles deveriam criar/apresentar uma proposta de intervenção que visasse sua resolução e/ou minimização dos problemas urbanos locais. É relevante frisar que a explicação/delineamento, bem como, a possível resolução do problema deveria partir das próprias visões e vivências dos alunos.

Deste modo, no decorrer da organização da prática procurou-se escolher uma temática com pertinência para a vida dos alunos, que pudesse contribuir para levar os sujeitos envolvidos a serem capazes de refletir/ questionar seu local de morada. Assim como, dialogar com os gestores públicos, não somente na perspectiva da constatação e da indicação dos problemas e de seus impactos nos locais onde ocorrem, nem no sentido de realizar apenas uma crítica, mas sim na construção de possíveis soluções que pudessem de fato melhorar o cotidiano das pessoas que convivem com tais situações.

A prática foi desenvolvida procurando entrelaçar ensinagens sobre a cidade através da rede social $\mathrm{Fa}$ cebook. Deste modo, os alunos poderiam utilizar a referida rede social no decorrer de todos os momentos de desenvolvimento do trabalho, em data previamente agendada os grupos deveriam "postar" suas propostas na página no Facebook da Prefeitura Municipal de Capivari do Sul.

Os alunos que possuíssem perfil de usuário no Facebook poderiam utilizar as mesmas para postarem seus trabalhos, os que não tinham ou não quisessem se expor não precisariam criar, podendo utilizar o perfil de usuário da pesquisadora. No entanto, todos decidiram fazer a montagem da proposta, bem como a publicação em seu próprio perfil.

No decorrer da atividade, negociamos (pesquisadora/professora/alunos) que não poderiam ser utilizadas expressões agressivas ou muito informais, como gírias, por exemplo, pois o trabalho pretendia utilizar os conhecimentos geográficos para propor melhorias para a cidade e não apenas permanecer tecendo críticas ou elogios, como a maioria dos outros comentários que já estavam publicados nas páginas governamentais.

Após a aula onde combinamos o que os grupos teriam que fazer, passamos mais quatro aulas pensando em como faríamos, experimentando caminhos, encontrando problemas e buscando soluções para resolvê-los, se motivando, se decepcionando, enfim, aprendendo, às vezes até sem perceber. Na quinta aula os alunos publicaram suas propostas na página do Facebook da Prefeitura de Capivari do Sul e no Perfil no Facebook do Prefeito de Palmares do Sul, algumas horas mais tarde na mesma data recebemos uma resposta da Prefeitura Municipal de Capivari do Sul, conforme figura 1, já o Prefeito de Palmares do Sul não se manifestou sobre o assunto.

Figura 1 - Resposta da Prefeitura de Capivari do Sul

A

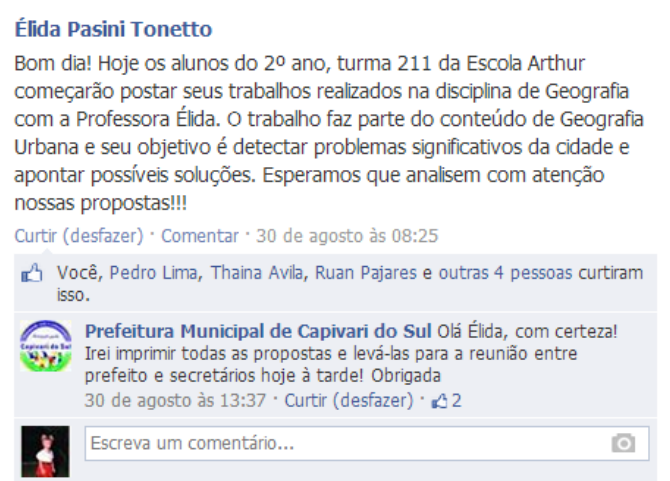
Organização: TONETTO, 2013

Foram sete propostas, sendo seis relacionadas a Capivari do Sul e uma relacionada a Palmares do Sul, as quais tiveram os seguintes títulos: Iluminação pública no Jardim Formoso, Grades nas bocas de lobo de Capivari do Sul, Preocupação da comunidade, Cães abandonados em Capivari do Sul, Semáforo e a Rótula RSC 101 pede socorro. Percebe-se que alguns dos problemas escolhidos pelos alunos não dizem respeito à macro preocupações urbanas, mas por fazerem parte de seu cotidiano e os interessarem, foram respeitados e mantidos como temáticas de investigação. 
Cabe ressaltar, que a temática Geografia Urbana, escolhida para a construção das atividades práticas não foi o foco das discussões, pois as potencialidades poderiam ser avaliadas em diferentes temáticas estudadas pela Geografia, as análises e discussões mais relevantes para este estudo foram aos caminhos que os alunos, sob orientação da professora, encontraram para resolver o desafio proposto, pois nestes percursos foram sendo construídas as aprendizagens, que ofereceram mais significado aos conteúdos geográficos.

Neste sentido, cabe uma consideração importante, ao abordar a temática de estudo o mais relevante foi salientar aos alunos "o que fazer" e não "como fazer", na possibilidade oferecida a eles em descobrir "como fazer", é que foram criadas e (re)criadas as potencialidades das redes para a Geografia. Deste modo as potencialidades foram sendo evidenciadas ao longo da construção das atividades, e analisadas através de um olhar embasado no arcabouço teórico que ampara este estudo.

Para isto, observou-se que as redes sociais podem contribuir para construir ou instigar a autonomia do aluno, que nos casos observados, tiveram que escolher seus temas, e optar por formatos de apresentação de um trabalho que ficaria visível ao público. Além de transitarem por uma série de informações e instrumentos que estavam à disposição, nas quais eles precisavam ser autônomos para decidir entre os mais adequados, transformando em um conhecimento útil para a comunidade, e que ao mesmo tempo era passível de julgamento por essas pessoas, como mostra a figura 2 .

Figura 2 - Trabalho sobre iluminação pública do bairro Jardim Formoso

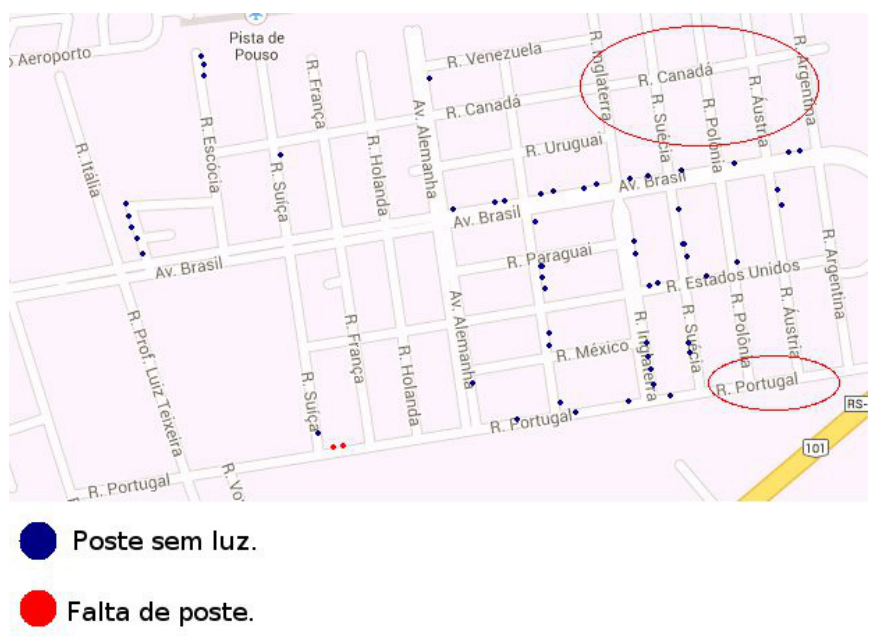

Organização: TONETTO, 2013.

Além disso, foi possível perceber o potencial de interatividade presente nas redes, onde os alunos estabeleceram diversas formas de interagir não somente com a máquina ou com o seu próprio grupo e a professora, e sim com diferentes informações, fornecidas tanto por sites, quanto também por pessoas que encontravam-se naquele instante distantes da sala de aula, mas a elas conectadas através das redes, contribuindo com as discussões realizadas. Esse tipo de interatividade é descrita por Lemos como eletrônico-digital, que "possibilita ao usuário interagir não apenas com o objeto (a máquina ou a ferramenta), mas com a informação, isto é, com o conteúdo" (2010, p. 114).

Através dos tipos de interatividade propiciados pelas redes foi possível também a construção de autoria, tanto individual quanto coletiva, pois para a escolha do problema urbano local e suas possíveis soluções, foram levados em consideração as opiniões dos colegas, e em muitos trabalhos foi requisitada a colaboração de outros usuários da rede, seja através do Bate-papo, seja através de enquetes, assim, observa-se a construção coletiva de materiais, que oferecem também a possibilidade de serem (re)utilizados de diferentes formas por professores e alunos.

Neste sentido, a autoria que seria possível entre as paredes, aluno/professor, foi potencializada pelas redes e transformada em alguns casos em autoria coletiva, aluno/professor/usuários do Facebook. As atividades desenvolvidas demonstraram possibilidades coletivas, colaborativas e compartilhadas "na autoria de materiais didáticos digitais, visando uma inserção de produção e não apenas de (re)produção." (GIORDANI; TONINI, 2013, p. 1905).

Foi possível perceber os potenciais das redes sociais também quanto a visibilidade, que permite o (re) pensar do trabalho, levando o aluno e o professor a verificarem possíveis erros, limitações do que foi proposto e vislumbrar outras possibilidades. Todas estas potencialidades foram operacionalizadas através de ferramentas específicas disponibilizadas na rede social Facebook, como "conta de usuário e perfil", "curtir", "comentar", "compartilhar" e "páginas", cada uma delas apresentou funções que foram apropriadas de diferentes formas pelos alunos, ao longo do caminho percorrido por cada um para a construção de seu material.

É importante salientar que as operacionalidades que mais interessam a este estudo ultrapassam as infraestruturas tecnológicas existentes ou não nas escolas, apesar de serem necessárias e fazerem parte da agenda de necessidades da instituição escola, cabe destacar que este não foi o foco desta investigação. 0 enfoque desta análise diz respeito ao instrumental disponibilizado na/através das tecnologias digitais e, que podem efetivamente operacionalizar as potencialidades construídas pelas redes através de seus membros.

A partir deste entendimento suscitado em meio ao processo investigativo, houve um novo olhar sobre algumas ferramentas disponíveis no Facebook, as quais foram denominadas de operacionalidades. Dentre elas, se destacam os seguintes instrumentos: conta de usuário e perfil, curtir, comentar, compartilhar, bate-papo e página, as quais foram utilizadas para diferentes objetivos no decorrer da prática escolar das aulas de Geografia.

A conta de usuário é utilizada para fornecer acesso ao Facebook, já o perfil é utilizado para identificar o usuário na rede social, no perfil é possível disponibilizar inúmeros tipos de informações, bem como definir uma série de configurações de privacidade. Se os 
grupos não tivessem a conta de usuário a realização do trabalho seria limitada, pois os alunos poderiam postar através da conta da professora, por exemplo, mas os outros recursos não seriam utilizados por eles, o que diminuiria os potenciais da ferramenta.

A ferramenta "comentário" juntamente com o bate-papo contribui para a construção de autoria coletiva, no momento em que permite a exposição das opiniões de inúmeras pessoas que se encontram em locais distintos, além da interatividade em vários níveis, como foi discutido anteriormente. Sendo que o comentário fornece o tipo de comunicação assíncrona e permite maior visibilidade, já o bate-papo realiza os dois tipos de comunicação síncrona e assíncrona, podendo ser realizado com quantas pessoas o usuário desejar, mas oferecendo também a possibilidade de maior privacidade entre os membros que se comunicam.

Os recursos "curtir" e "comentar", por exemplo, foram utilizados como instrumentos de coleta de dados por um grupo de alunas, diminuindo investimentos, tempo, bem como maximizando o alcance da coleta, apresentando neste caso potencialidade e operacionalidade, figura $3 .$.

Figura 3 - Enquete para coleta de dados

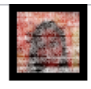

Fulana de Tal

16 de agosto

Nós alunas Fulana de Tal, Ciclana da Silva e Beltrana Santos, da turma 211 da Escola Arthur juntamente com a professora de Geografia Élida Pasini Tonetto estamos fazendo um trabalho de Geografia Urbana e nosso grupo gostaria de saber sua opinião: O QUE VOCÊ ACHA SOBRE A INSTALAÇÃO DE UMA SINALEIRA NO TREVO DA RSC 101 COM A RS 040?

OBS: Quem concorda curte.

Curtir (desfazer) $\cdot$ Comentar

Você, Isadora Lermen, Déia Ávila Vini Fraga, Juliana Silva e outras 51 pessoas curtiram isso.

2. Milene Dutra Seria ótimo, só que já se acidentou nesse trevo sabe que a imprudência e falta de atenção por parte de alguns motorista é enorme, assim, uma Sinaleira ajudaria muito. 16 de agosto às $09: 46 \cdot$ Curtir (desfazer) - 16

Faפ Dudi Famer Dos Santos Esta sinalização já foi posta uma vez. Mas devido ao descer do sol a tarde na 040 , parecia que o sinal fica hora aberto, hora fechado e acabou prejudicando mais, provocando mais transtornos na alta temporada. 16 de agosto às $13: 53 \cdot$ Curtir

(ardoso seria uma boa alternativa

6 de agosto às $22: 32 \cdot$ Curtir

Catia Nunes 4111111111

8 de agosto às $20: 45 \cdot$ Curtir

Organização: TONETTO, 2013.

0 instrumento "compartilhar" equivale ao publicar e permite como o próprio termo sugere o compartilhamento das informações, para a opção compartilhamento estão disponíveis alguns mecanismos de controle da privacidade, como "Público, Amigos, Amigos exceto conhecidos, Somente eu, Personalizado, ou em um Grupo específico", isso permite definir o grau de visibilidade que se pretende alcançar com o compartilhamento do conteúdo. Nos trabalhos a ferramenta foi utilizada no sentido de oferecer visibilidade a proposta, especialmente para a Prefeitura Municipal e para a cidade de Capivari do Sul.
A ferramenta "página" é utilizada para manter uma relação mais próxima com um determinado público, sendo possível fornecer materiais de interesse para esse mesmo público, os usuários/simpatizantes têm a opção de "curtir" a página e assim receberão os conteúdos postados nela. Dependendo das configurações realizadas pelo administrador da página é possível fazer postagens e comentários nestes espaços. No decorrer da prática os alunos utilizaram as páginas de um modo geral para coletar informações e também para postarem suas propostas.

A opção "marcar" é utilizada para adicionar um conteúdo (imagem, som, texto) a Linha do tempo de outro usuário, simultaneamente a postagem aparece na Linha de quem postou e nas outras pessoas que foram "marcadas", um detalhe importante diz respeito às configurações definidas por cada usuário, pois é possível definir que as marcações não aparecem diretamente a Linha do Tempo, dependendo de aceitação do dono do Perfil que foi marcado.

Utilizando esta operação específica um grupo postou seu trabalho e marcou o Perfil do Prefeito de Palmares do Sul em sua postagem, mas como seu perfil estava configurado para ter prévia aceitação antes da publicação, o trabalho acabou não sendo acrescentado na Linha do Tempo do Prefeito. Além disso, não houve uma resposta ou posicionamento em relação à temática discutida, no entanto, houve manifestações através de comentários e curtidas no perfil da aluna.

Explicitadas as funções das ferramentas disponíveis no Facebook, nota-se que elas operacionalizam as potencialidades que a referida rede social oferece. Neste sentido, elas foram apropriadas pelos alunos a fim de construírem uma resposta ou um caminho ao desafio colocado pela professora/pesquisadora no início do processo investigativo, bem como as demais situações que surgiram no decorrer do percurso.

Deste modo, considerar estas potencialidades e operacionalidades, além de outras que podem ser (re) criadas na/através das redes leva a uma profunda reflexão sobre as práticas escolares da Geografia, não apenas tecnificando as aulas, mas recriando a prática comunicativa, entendendo que o professor/a não é o único responsável pelo ensino (emissão), e o aluno não é o único responsável por sua aprendizagem (recepção), mas há sim um processo imbricado entre os dois, ou comunicação Todos-todos conforme aponta Lévy (1999). Neste sentido, as potencialidades das redes ajudam a mesclar estas funções, retirando esses atores das suas posições originais e colaborando para a transformação das ensinagens da Geografia.

Ao analisar as atividades construídas, o temor ao início da pesquisa vai se esvaindo, pois começamos a perceber, inspiradas nas orientações da própria Tonini (2013), que nenhuma prática é tão simples quanto parece, suas simplicidades ou complexidades estarão mais ou menos evidentes, dependendo das lentes teóricas que cada um utilizar para lançar seus olhares sobre 
elas, bem como os artefatos existentes em nosso meio não são apenas ferramentas para "enfeitar", "alegrar" ou "modernizar" nossas aulas, eles são ou podem ser potencializadoras de diferentes formas de aprender.

Deste modo, os potenciais e as ferramentas que as operacionalizam apresentadas no decorrer deste estudo não são uma mochila escolar pronta para o uso em qualquer aula de Geografia, e sim algumas possibilidades experimentadas e vivenciadas enquanto professoras/pesquisadoras de Geografia que buscam conectar a sala de aula ao mundo contemporâneo, mudando o status das aulas de Geografia de offline para online.

Esta mudança não representa apenas uso da técnica em sala de aula, mas sim a busca pela construção de processos de aprendizagens significativos em Geografia, através das potencialidades oferecidas pelas redes sociais, que representam uma forma contemporânea de comunicar/interagir presente no cotidiano dos alunos.

Uma série de questionamentos e análises emerge da realização desta prática e deixam um gancho para o desenvolvimento de outras práticas, que podem revelar novas e inesperadas potencialidades/operacionalidades que as redes suscitam. Enquanto pesquisadoras/professoras de Geografia conectadas (ou tentando se conectar) e que percebem que espaço e ciberespaço não são entidades distintas, mas sim um novo desafio que a espacialidade contemporânea apresenta Massey (2012).

\section{Referências}

ANASTASIOU, Léa da Graças Camargos. Ensinar, aprender, aprender e processos de aprendizagens. In: IV Seminário de Desenvolvimento Profissional Docente "Planejamento e Avaliação da Aprendizagem na Educação Superior", 2011, Santana do Livramento. Anais eletrônicos... Santana do Livramento: UNIPAMPA, 2011. Disponível em: http://eventos.unipampa.edu.br/seminariodocente/files/2011/03/Oficina-10-Estrat\%C3\%A9gias-metodol\%C3\%B3gicas.pdf. Acesso em 16 jan. 2013.

BAUMAN, Zygmunt. Modernidade Líquida. Tradução de Plínio Dentzien. Rio de Janeiro: Jorge Zahar, 2001.

HINE, Christine. Etnografia virtual. Barcelona: Editorial UOC, 2004.

LEMOS, André. Cibercultura: tecnologia e vida social na cultura contemporânea. 5 ed. Porto Alegre: Sulina, 2010.

LÈVY, Pierre. Cibercultura. Rio de Janeiro: Ed. 34, 1999.

MASSEY, Doreen. Pelo Espaço: uma nova política da espacialidade. Tradução Hilda Pareto Maciel, Rogério Haesbaert. 3 ed. Rio de Janeiro: Bertrand Brasil, 2012.
PARAÍSO, Marlucy Alves. Metodologias de pesquisas pós-críticas em educação e currículo: trajetórias, pressupostos, procedimentos e estratégias analíticas. In: MEYER, Dogmar Estermann; PARAÍSO, Marlucy Alves (Orgas.). Metodologias de pesquisas pós-críticas em educação. Belo Hotizonte: Mazza Edições, 2012. PRETTO, Nelson. Uma escola com/sem futuro. Campinas: Papirus, 1996.

RECUERO, Raquel. Redes Sociais na Internet: Considerações Iniciais. In: Revista E Compós, v. 2, 2005. Disponível em: http:/www. ufrgs.br/limc/PDFs/redes_sociais.pdf. Acesso em: 10 fev. 2013.

SANTANA, Camila Lima Santana e. Redes Sociais na Internet: Potencializando interações sociais. In: Revista digital Ipertextus. UFPE, Pernambuco, v 1, n. 1 2007. Disponível em: <http:// www.hipertextus.net/volume1/ensaio-05-camila.pdf>. Acesso em: 25 fev. 2013.

SANTOS, Edméa Oliveira dos. Educação online: cibercultura e pesquisa -formação na prática docente. Salvador, 2005. Originalmente apresentada como tese de doutorado, Universidade Federal da Bahia, 2005. Disponível em: <http://www. dominiopublico.gov.br/pesquisa/DetalheObraForm.do?select action=\&co_obra=154202 Acesso em: 01 fev. 2013.

SIBILIA, Paula. Redes ou paredes: a escola em tempos de dispersão. Tradução Vera Ribeiro. Rio de Janeiro: Contraponto, 2012.

SILVA, Marco. Sala de aula interativa: educação, comunicação, mídia clássica, internet, tecnologias digitais, arte, mercado, sociedade, cidadania. 6. ed. - São Paulo: Edições Loyola, 2012.

TONINI, Ivaine Maria. Movimentando-se pela Web 2.0 para ensinar Geografia. In: CASTROGIOVANNI, Antonio Carlos; TONINI, Ivaine Maria; KAERCHER, Nestor André (Orgs.). Movimentos no ensinar Geografia. Porto Alegre: Impressa Livre: Compasso Lugar-Cultura, 2013.

Notas sobre imagens para ensinar Geografia. VALLADARES, Marisa; OLIVEIRA JUNIOR, Wenceslao. Dossiê sobre imagens escolares. Niterói: UFV, 2013. (no prelo)

VEIGA-NETO, Alfredo. Crise da modernidade e inovações curriculares: da disciplina para o controle. In: XIV Encontro Nacional de Didática e prática de ensino. Trajetórias e processos de ensinar e aprender: sujeitos, currículos e culturas . Anais... Porto Alegre, 2008. Disponível em: < http://www.grupodec.net.br/ebooks/ CrisedaModernidadeAlfredo.pdf $>$. Acesso em: 20 set. 2013.

Currículo: um desvio à direita ou Delírios avaliatórios. In: X Colóquio sobre Questões Curriculares e VI Colóquio Luso-Brasileiro de Currículo, Belo Horizonte: UFMG, 2012. Disponível em: <http://www.fe.unicamp.br/temporarios/

veiga-neto-curriculos-delirios-avaliatorios.pdf $>$. Acesso em: 02 out. 2013.

; SARAIVA, Karla. Educar como arte de governar. In: Currículo sem Fronteiras, v.11, n.1, pp.5-13, Jan/Jun 2011. Disponível em: <http://www.curriculosemfronteiras.org/vol11iss1articles/veiga-neto-saraiva.pdf>. Acesso em: 02 out. 2013.

\begin{abstract}
This study analyzes the possibilities and operability of school practices in Geography in the appropriation of online social networks for meaningful learning. For this, we identify the elements boosters potential offered by digital platforms and evaluated how their operability occur in teaching Geography. With these findings it possible to reflect on the elements that contribute to the implementation of school practices with social networks in Geography. The theoretical lines of research are woven between the concepts of space, cyberspace and also transits two key locations: the school and the network, these sites that permeate any discussion of this study. The theoretical-methodological approach is supported in the post-critical research in education as they allow to understand how the process of learning on digital platforms from methodological tears brought by contemporary technologies. Facebook is the locus to analyze new ways of communicating, which subjectify subjects and engender new forms of ensinagem. The results show different strengths and operated online social networks, representing not only the use of the technique in the classroom, but the search for the construction of meaningful learning processes in Geography, through social networks, which represent a contemporary language in this daily lives of students.
\end{abstract}

Keywords: Geography Online - Technology - School Practices 